\title{
Analysis of positioning of sanatorium-resort institutions of the Republic of Bashkortostan and their promotion using innovative technologies
}

\author{
Konstantin Kuzminyh, and Regina Galkova* \\ Ufa State Petroleum Technological University, 1 Cosmonauts st., 450062 Ufa, Russian Federation
}

\begin{abstract}
Today, sanatorium and resort institutions are undergoing a difficult period, in particular due to the spread of "Covid19" infection. It is assumed that against the backdrop of the crisis, domestic tourism will develop more, respectively, tourists will prefer to book tickets themselves, studying information on Internet resources. In this case, it is impossible to increase the efficiency of the enterprise and increase the demand for services without the use of innovative IT technologies to sanatoriums. The study showed that the activity of most sanatoriums on international online sites is very weak, as well as many of them do not conduct news feeds on official sites, ignore social networks as an effective mechanism for their promotion, as a result of which circumstances arise when the services provided by sanatoriums do not meet the expectations of vacationers. It should be recognized that the level of service in the sanatorium requires an increase, accordingly, it is necessary to carry out activities to position and qualitatively improve work on online services. The acquisition of competitive advantages and the preservation of loyalty of guests is the key functions of positioning and promoting sanatorium and resort institutions, which in turn will contribute to the management of the sustainable development of the territory of the Republic of Bashkortostan.
\end{abstract}

\section{Introduction}

The Republic of Bashkortostan is one of the most picturesque republics of Russia with a fairly developed sanatorium and resort sphere.

The sanatorium and resort complex of Bashkiria includes more than 150 institutions, of which 26 are the largest sanatorium and resort enterprises. The bulk of sanatorium and resort institutions appeared in the Soviet period. At the same time, calm and pacification are perhaps two main words that characterize rest in Bashkir sanatoriums.

However, at the moment, sanatorium-resort institutions are undergoing a difficult period, in particular due to the spread of a new coronavirus infection. All local resorts were suspended by decisions of regional authorities. Since March, booked mass rides, banqueting events, closed pools have been canceled, and there has been a decrease in the

\footnotetext{
* Corresponding author: regina.galkova@rambler.ru
} 
provision of medical and cosmetological services. All these consequences of restrictions on health resorts significantly affected the financial and economic component of enterprises, despite the fact that some sanatoriums in the republic continue to act as an observatory for incoming citizens.

It is assumed that against the backdrop of the crisis, domestic tourism and tourism will develop more in their region so that tourists can easily travel with their families and return. Accordingly, due to this, the old tour rating model will no longer work, and tourists will now prefer to book tickets themselves. Moreover, before booking, consumers often study information on Internet resources, such as the sanatorium site, recall sites, social networks.

It is only worth remembering that the profile age of the target audience of sanatoriums is 40-70 years. And even if the sanatorium plans to specialize in the older age group of 65 years and older, then it should be borne in mind that many of them buy vouchers their children, 30-50-year-olds. All of them are also active users of the Internet. This is due to the fact that the technological capabilities of modern "gadgets" are characterized by mobility, which allows you to quickly meet information or other needs [1]. The selection criteria are photos, reviews left by other consumers, and the cost of living. Accordingly, information technology will contribute to improving the efficiency of the enterprise and increasing the demand for services. So, if the company wants to actively grow and develop, it is impossible to do without the use of innovative IT technologies in this case.

To promote management of sustainable development of the territory it is necessary to solve a system problem: big information reorganization of work of advertizing and marketing in the Internet, explanation is necessary that, for example, the resorts of Bashkiria - are better and cheaper than foreign.

Among all existing sanatorium institutions, differing in the level of the development and rendering services, it is quite often heavy to vacationer to decide on the choice of sanatorium and to estimate the level of his service. All this creates need of development of a regional system of positioning on the basis of marketing strategy [2]. Therefore especially relevant is a positioning and advance of sanatorium services in online services for the purpose of expansion of the Russian and foreign markets of medical and improving tourism.

\section{Research materials and methods}

The object of the study is sanatorium and resort institutions of the Republic of Bashkortostan, the subject is the marketing strategy of sanatorium institutions.

The empirical base was made up of sites of regional sanatoriums, pages on international online sites of reviews of TripAdvisor and TopHotels, as well as pages of sanatoriums on social networks such as Vkontakte, Youtube, Instagram, Facebook and Odnoklassniki.

To analyze the positioning of sanatorium and resort institutions in Bashkiria, it is necessary to study the range of services provided, the uniqueness of location, information on such international sites as TripAdvisor, TopHotels, as well as on social networks and sanatorium sites. Especially attention needs feedback, receiving prompt and high-quality feedback, the relevance of data on the sanatorium, active references to additional communications, attendance and manifestations of loyalty by guests.

\section{Analysis of positioning of sanatorium-resort institutions on Internet resources}

So, TripAdvisor - one of the leading sites for reviews, in essence, is a guest book and a place where people record the ups and downs of their vacation in the interests of hotel 
owners and future guests. But this guest book is located on the Internet, where its participants continue to exchange advice, memories and complaints about their trips for a long time, even after their vacation has come to an end [3]. During the analysis of the positioning of the sanatoriums of Bashkiria on the TripAdvisor website, it was revealed that, for example, in the case of the leading republican sanatorium Yangan-Tau, a good page on the TripAdvisor with all the necessary information and excellent technical and stylistic quality of photographs is noted. But most of the sanatoriums, namely 18 of 26 , do not have a page at all and ignore this international platform as an effective mechanism for their advancement. It should be noted that Yangan-Tau has the most reviews, including with an excellent rating, the Krasnousolsky sanatorium is in second place. However, almost all have negative reviews (Figure 1).

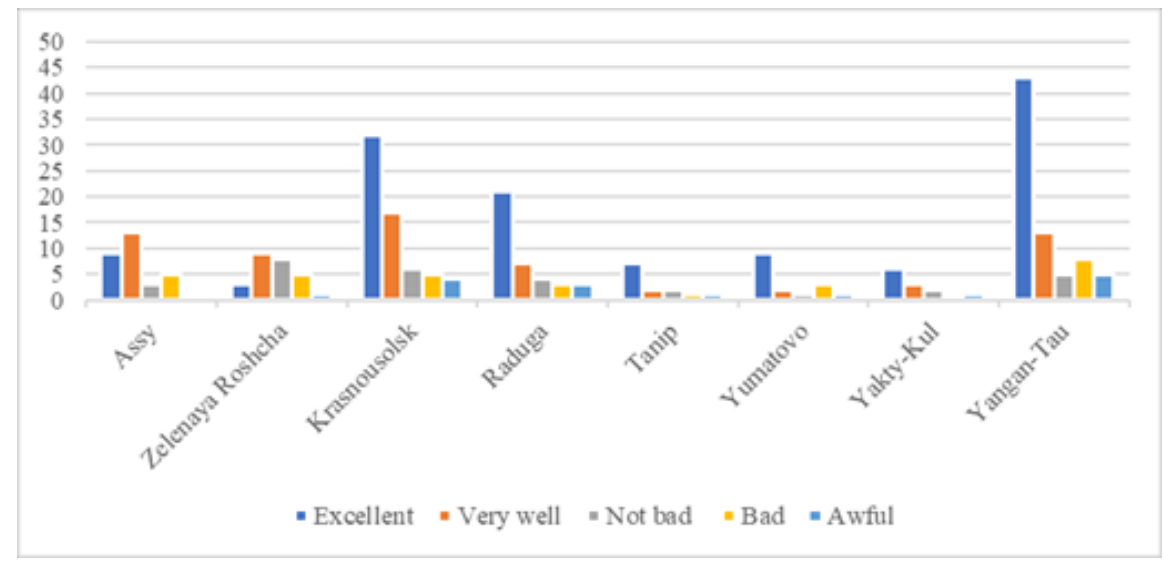

Fig. 1. The number and quality of reviews on the TripAdvisor website

On the pages of all sanatoriums of the republic there is completely no reaction to the reviews of visitors, there is no feedback, there are absolutely no foreign reviews, despite the fact that not only Russian, but also foreign tourists visit the sanatorium. Not rarely, the negative review "hangs" last on the page, attracting attention, which is the problem of almost all the investigated regional sanatoriums. Do not forget that for many foreign guests Russia, especially the regions, is an exotic direction. Therefore, they try to be reinsured they read reviews, ask questions in specialized forums, etc. Foreign guests are accustomed to prompt feedback on their comments, especially on complaints or claims, and the lack of reaction on the network most often repels potential guests.

Another such large site is the TopHotels feedback site, which represents the catalog and rating of hotels in the world and is the leader in popularity in its segment. However, in the case of the sanatoriums of the Republic of Bashkortostan, a similar situation has formed on the TopHotels, since work on this site is very weak, most of the reviews have been received quite a long time ago. The study revealed that Yangan-Tau also leads the TopHotels, since it also has the most reviews, including with an excellent rating, in second place is the Assy sanatorium. However, as shown in the graph, as in the case of TripAdvisor, there are negative reviews, the activity on the pages is very weak, and in general the number of reviews leaves much to be desired (Figure 2). 


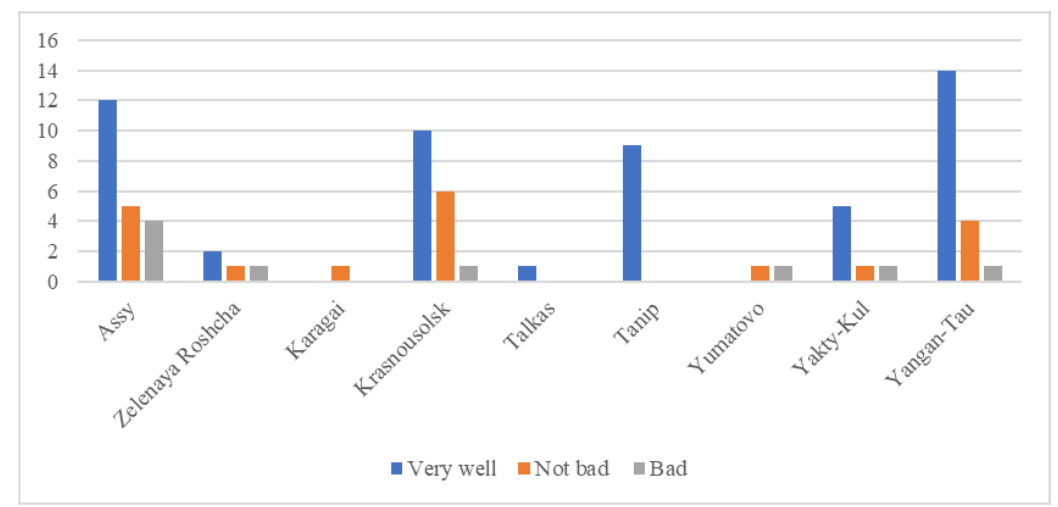

Fig. 2. Number and quality of reviews on the TopHotels website

Further, the study was carried out on the informative nature of official feedback sites, obtaining prompt and high-quality feedback, the relevance of data on the sanatorium, active links to additional communications, attendance and loyalty by guests of sites and social networks. A study of existing sites and social networks showed that many of them do not conduct news feeds on official sites and ignore social networks as an effective mechanism for their promotion. The most popular social networks among sanatoriums are VKontakte and Instagram (Fig. 3).

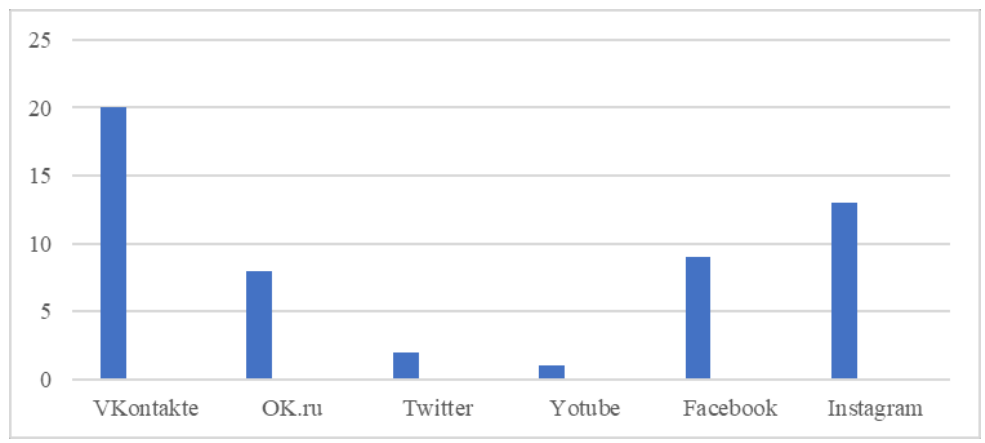

Fig. 3. Location of sanatoriums in social networks

Although, usually in most sanatoriums in the summer reaches full load, and vacationers receive a wide range of treatment, but this is sometimes all limited. And this year, in connection with the current situation, demand has changed significantly, and in order to use all the opportunities to raise the attractiveness of spa holidays among the population, it is necessary to strengthen work in the field of advertising and marketing [4].

Every year, tourists make more and more requirements for infrastructure and service quality, comparing the experience of obtaining foreign resort services. However, when studying the sanatoriums of the region, disparity and insufficiency of information on the Internet resources of regional sanatorium and resort institutions were noted. In addition, not a single sanatorium had a place to accommodate the republican tourist brand TerraBashkiria.So, while many regional sanatoriums do not have a single page on the social network, others conduct active SMM [5].

It should also be noted that within the framework of the IV specialized exhibition "Forum of travel industry" for the leaders of the sanatorium-resort sphere and the tourism industry of Bashkiria, there was a unique opportunity to take part in the business training "Sanatorium-resort information vacuum: problems and solutions for improving the brand and loyalty of guests," touching on topical topics for employees of the sanatorium-resort 
sphere. However, of all the invited workers and managers, only two representatives from sanatorium and resort institutions attended the training.

All this indicates the lack of scale of thinking, the lack of synergistic interaction between sanatorium and resort institutions and the tourist sphere of the republic. The leaders of sanatoriums are not even interested in solving the problems of positioning themselves in the service market and creating their positive image. After all, the image of any sanatorium is primarily an audiovisual perception of the object, the constantly maintained trust of vacationers, the involvement of guests in the development of sanatoriums and relationships commensurate with "eternal friendship" [6].

It follows that the main problem of positioning regional sanatorium-resort institutions is the lack of mutual understanding between sanatoriums and their possible guests, which soon arises into a disagreement between them when choosing services or in accordance with the quality of services and price. In turn, this is the reason when sanatoriums do not meet consumer expectations [2].

Thus, for sanatoriums, the Internet is an important promotion channel than for any other market, which also cannot be underestimated, since IT has firmly entered the lives of people and has become a mandatory element of the "sales chain." Already today it is difficult to imagine that buying a ticket can do without visiting the sanatorium website, as well as without analyzing the reviews of it on the Internet by a potential buyer.

The site of the sanatorium today is the basis for organizing sales of tickets and services of the sanatorium through all communication channels. So, if the leaders of the sanatorium give advertising, for example, on television, but at the same time the services are not sufficiently represented on the sanatorium's website, or have a weak conversion, then a significant part of the budget will be spent in vain. But an impeccable site is still only the first step, since it is necessary to form a policy so that potential guests find a sanatorium, not only by name in the search engine, but also when they choose a sanatorium in a particular region, or when they are looking for methods of treating their illness. Also, it is very important that information about the sanatorium is found on various Internet resources and has numerous positive reviews. If the sanatorium wants to attract new guests, then it is necessary to remember the "rule of three contacts." So that the new user draws attention to a new product/service/sanatorium for himself, he needs to see information about him at least three times.

The process of selling a spa ticket accompanies many stages, ignoring which in most cases leads to a disruption of sales. Therefore, the built-in full cycle of integrated Internet promotion is simply necessary in advertising and marketing activities, so that the sanatorium site customers easily find in search engines, moreover, not only by the name of the sanatorium, but also by medical and regional requests. And this is precisely the work on seo-optimization, which by the nature of the tasks belongs to the field of IT and marketing, which forms the basis of the Internet promotion of sanatorium services [7].

In parallel with the seo promotion, it is necessary to disseminate the necessary information in the network, which corresponds to the main positioning of the sanatorium, will strengthen its best parties, talk about the effectiveness of treatment and a wonderful service, about the opportunities to familiarize yourself with the sights of the region and so on [8]. This includes: SMM promotion or promotion through social networks; reputation management at online sites; monitoring of information placement in directories; publication of problematic articles, advertising on specialized medical websites and on the main websites of specialized regions; direct-advertizing. In parallel with this, it is important to competently work with the client base of the sanatorium, providing information support within the framework of post-sale services. This is very useful for promoting the site and for encouraging "word of mouth" and repeated visits. 
All these paths should be worked out by regional sanatoriums. But until this minimum is worked out, it is impractical for sanatoriums to consider other channels of information promotion, especially within the framework of a strict restriction on the advertising budget. It should also be borne in mind that it is possible to start promoting only when the sanatorium site meets all modern requirements, and the "descriptive packaging" of the sanatorium maximally reflects all its competitive advantages, competently and fully describing the services of the sanatorium.

However, there is also a problem in the absence of staff engaged in promotion, or if there is an appointed employee, then he does not have the necessary professional skills to competently build the marketing strategy of the sanatorium.

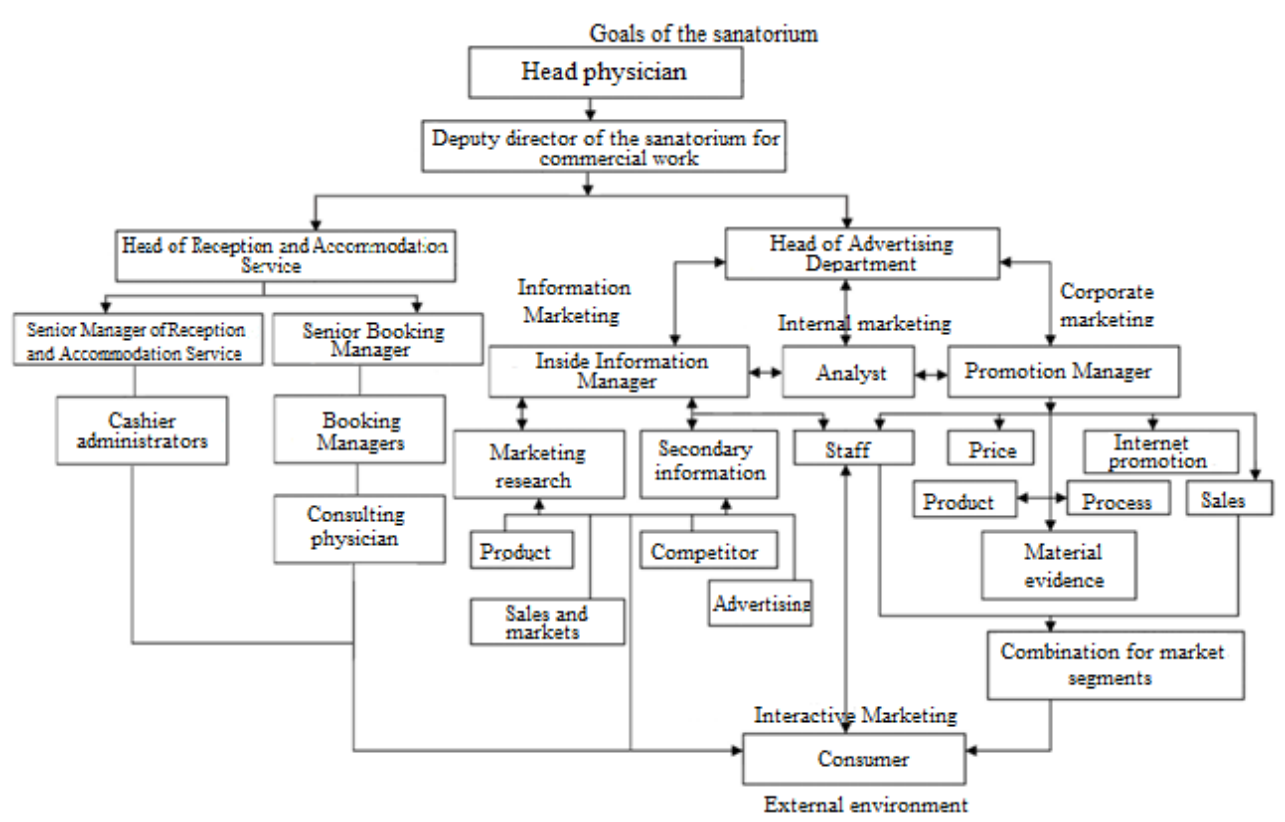

Fig. 4. Organizational structure

So it happens that the reception and placement service is combined with the booking department, and this is fraught with a decrease in sales growth. Also, in regional sanatoriums, the absence of an advertising manager is noted, and his position is replaced by an employee who does not have suitable professional skills. In addition, often the names of divisions and posts do not correspond to their functionality, for example, the marketer performs the work of the booking manager. And in order for the marketing service to fulfill its tasks, it is necessary that it be led by the deputy chief physician for commercial work. Therefore, the following organizational structure of the sanatorium is proposed, which would allow more efficient marketing activities (Fig. 4). The organizational structure may differ in different sanatoriums, however, the separation of the reception and placement service from the reservation department and the advertising department is mandatory. All these events will allow regional sanatoriums to become more effective, which will undoubtedly contribute to sales growth.

\section{Conclusions}

1. Thus, it is quite obvious that the level of service in the sanatoriums of the Republic of Bashkortostan requires an increase, accordingly, it is necessary to carry out activities to 
position them and qualitatively improve work in online services, which will contribute to the conquest and preservation of the competitive advantages not only of the sanatoriums themselves, but also of the entire sanatorium and resort sphere of the region.

2. All sanatoriums use social media in every way to promote their services [5]. It is recommended that enterprises pay attention to working on the internal marketing positioning of the sanatorium: for example, involve employees in the planning and conduct of marketing events. Further, to maintain relations with young people, it is necessary to create accounts on social networks and constantly update information in them, and to attract new customers - to send press releases to the media. It is also recommended to pay attention to seo promotion.

3. The formation and preservation of a positive image of sanatoriums on Internet resources is extremely time-consuming and painstaking process, on which the competitive ability of enterprises depends. That is why the acquisition of competitive advantages and the preservation of loyalty of guests is the key functions of positioning and promoting sanatorium and resort institutions of the Republic of Bashkortostan, which in turn contributes to the management of the sustainable development of the territory.

\section{References}

1. A. M. Vetitnev, YA. A. Ashkinadze, Organization of Internet technologies in the sanatorium and resort complex: monograph (2016)

2. M. S. Oborin, News of the Far Eastern Federal University. Economics and development, 1 (2015)

3. A. Ahani, M. Nilashi, O. Ibrahim, L. Sanzogni, S. Weaven, International Journal of Hospitality Management, 80 (2019)

4. N. V. Katunina, E. A. Luneva, Marketing and Marketing Conference, 1 (2020)

5. Yu. V. Pupkova, Society: politics, economics, true, 8 (2018)

6. C. Han Lee, E. Ko, H. Tikkanen, M. Cao Tuan Phan, G. Aiello, R. Donvito, S. Raithel, Journal of Business Research, 67 (2014)

7. S. Deshmukh, K.J. Gamble, K.M. Howe, Journal of Corporate Finance, 46 (2017)

8. T.G. Pyadysheva, I.F. CHepurova, Socio-economic processes, 6 (2017) 